\title{
Comparison of Transanal Suture Rectopexy With Stapled Haemorrhoidopexy in Patients of Haemorrhoids: A Randomized Control Trial
}

\author{
Amit Jain ${ }^{1}$, Irfan Hussain Khan ${ }^{2}$, Kuldeep Poonia ${ }^{3}$, Richa Jain ${ }^{4}$ \\ ${ }^{1}$ Assistant Professor, ${ }^{2}$ Senior Resident, ${ }^{3}$ Resident, ${ }^{4}$ Professor And Unit Head, Department Of General Surgery, \\ Sawai Man Singh Medical College, Jaipur
}

\begin{abstract}
Aim: To compare the transanal suture rectopexy with stapled haemorrhoidopexy in patients of haemorrhoids from clinical perspective.

Methods: From January 2014 to January 2016, Eighty patients of haemorrhoids from grade II to IV were randomly assigned to undergo either the transanal suture rectopexy $(n=40)$ or the stapled haemorrhoidopexy $(n=40)$. Outcome assessment was performed at 12 hours, 24 hours, 2 days, 1 month and at 6 months. Variables included operative time, post-operative complications, resolution of symptoms, and recurrence.

Results: Both the groups were comparable in terms of demographic data. No statistically significant difference was found between two groups in terms of operative time, post-op discomfort, urinary retention and VAS score at 24 and 48 hours. However the mean requirement of doses of analgesic diclofenac sodium $(0.85$ and 1.5 for the TR and SH group) differed significantly. Four patients in SH group developed prolapse at one month of post-op period, while in TR group this count was zero $(P=0.040)$. At six months of follow up seven patients of SH group had per rectal bleeding while only one patient from TR group has developed bleeding $(P=0.025)$. Four patients of the SH group had prolapse while no patient of TR group still had developed prolapsed at six month $(P=0.40)$. Patients rated TR as a better procedure than $S H$.

Conclusion: Though transanal suture rectopexy has similar operative time, and resolution of symptoms when compared to stapled haemorrhoidopexy; it certainly offers lower incidence of post-op pain and long term recurrence than stapled haemorrhoidopexy
\end{abstract}

Keywords: Chivate's procedure, transanal suture rectopexy, stapled haemorrhoidopexy, MIPH, haemorrhoids.

\section{Introduction}

Haemorrhoids are a common proctological disease that affects the quality of life in the patient population to a great extent. Nearly $4.4 \%$ to $36 \%$ of population is affected by haemorrhoids. The symptoms of haemorrhoids varies from painless bleeding to embarrassing and painful prolapsing mass The etiology of haemorrhoids has been extensively researched. They results from the increased pressure in haemorrhoidal plexus of vein, with degeneration of fibroelastic tissue in anal cushions acting as a contributing factor. Increased pressure in venous plexus can be due to straining during defecation, coughing or due to heavy weight lifting while degeneration of fibroelastic tissue may be a result of old age or due to genetic predisposition ${ }^{7}$.

Since the first mention of the disease in an Egyptian papyrus, the treatment of haemorrhoids has seen numerous modifications ${ }^{1}$. While the conservative treatment such as modification of diet, stool softners, topical medications and sitz bath do help in grade I haemorrhoids, invasive procedure become necessary in grade II, III, IV haemorrhoids. Rubber band ligation, piles plication, sclerotherapy ${ }^{6}$, and various cauterization methods are helpful in grade II haemorrhoids. But grade III, IV and failed grade II piles demands surgical intervention.

With the beginning of later half of the nineteenth century, haemorrhoidectomy by either MilliganMorgan or Ferguson technique has been the gold standard. In the 90`s Dr. Antonio Longo introduced stappled haemorrhoidopexy while Morinaga introduced Doppler guided haemorrhoidal artery ligation ${ }^{3,4}$. The basis of both of these techniques was cutting of the blood supply to haemorrhoidal plexus and fixation of anal cushions. Though they have gained popularity, the need for costly articles had kept them at bay in third world population.

But even after so many techniques recurrence remained a problem. The development of collaterals was the main contributing factor. In 2012 Dr Shanthikumar.D.Chivate presented the concept of transanal suture rectopexy $y^{5}$, in which ligation of blood vessels was done at two sites, thus decreasing the chances of collateral formation as well as dealing with the problem of mass proplapse.

We present this study with the aim of evaluating this new procedure and comparing it with stappled haemorrhoidopexy with regard to resolution of symptoms, ease of surgery, post-operative complications, and long term recurrence. 


\section{Study Design and patients}

This study was done at a tertiary level teaching hospital of the state of Rajasthan in India. It was a Randomised controlled clinical trial done between January 2013 and January 2016. All the patients of more than 18 years of age and who wanted to undergo surgery for haemorrhoids were enrolled for the study. Diagnosis of haemorrhoids was done by per-rectal examination and proctoscopy. Haemorrhoids were graded as per Goligher classification $^{8}$. Inclusion criteria was grade II,III and IV haemorrhoids. Exclusion criteria included any surgery in perineal area or rectum in last 5 years, thrombosed piles, malignancy, pregnancy and associated proctological diseases such as fistula in ano, anal fissure or anal abscess. The patients were informed about the details of the procedure and written informed consent was obtained. The patients were randomly grouped as; a) Transanal suture rectopexy group(TR group) b) Stappled haemorrhoidopexy group(SH group). Randomization was done with sealed envelope which were opened in operation theatre only. All the patients were operated by the same surgery unit led by a single surgeon. All study procedures were performed in accordance with the Declaration of Helsinki. 80 patients were enrolled in the study which were divided in two groups of 40 each.

\section{II. $\quad$ Surgical Methods}

1) Transanal suture rectopexy group (TR) - Patients were given P.C. Eenema in the evening 12 hours and 6 hours before the operative procedure. After giving spinal anaesthesia, patients were positioned in lithotomy with a little head low, which reduced the prolapsing pile masses. The laxed mucosal and submucosal tissues were placed in their anatomical position. Anal canal was lubricated with xylocaine jelly. A self illuminated slit with sliding valve proctoscope ${ }^{5}$, designed by $\mathrm{D}$ Chivate was used. After removing the sliding plate, dentate line was identified. The lax mucosa and submucosa was sutured to rectal muscles in two circumferential suture lines, $2 \mathrm{~cm}$ and $4 \mathrm{~cm}$ proximal to dentate line. First stitch was tied and the subsequent stitches which were $0.5-1 \mathrm{~cm}$ in length were double interlocked. The double interlocking avoided the purse string effect and thus the anal stenosis. Care was taken to not to take complete thickness of rectal wall in stitches. Since both the suture lines were above the dentate line in the insensitive part of anal canal, their was no problem of post operative pain. 2-0 polyglactin with round body $30 \mathrm{~mm} \mathrm{1/2}$ needle was used. Lax mucosa and submucosa was sutured in its original position and the blood supply to haemorrhoidal plexus was cut off at two places, thus decreasing the chances of collaterals formation which causes recurrence.

2) Stappled haemorrhoidopexy group(SH group) - Patients were prepared in the similar manner as with TR group by giving P.C Enema and were given spinal anaesthesia. After placing the patients in lithotomy position anal canal was massaged with xylocaine jelly and the circular anal dialator with obturator was introduced. Once the lax mucosa and submucosa has been repositioned, oburator was removed and anal dilator was secured with four stitches in the skin. With the help of anoscope, a circumferential suture line was taken $2 \mathrm{~cm}$ above the dentate line. The sutures were taken at the depth of mucosa and submucosa only with Prolene 2-0 suture. After the completion of suture line, a finger was inserted and both end of the suture tightened, so as ascertain the uniformity of the suture line. After the completion of purse-string suture, the circular stapler was opened and inserted in the anal canal, with the anvil placed beyond suture line. Then a surgical knot was made and the ends of the thread pulled out with the help of suture threader. The ends of the suture were also knotted externally and were given traction using artery forceps. The stapler was then tightened and then fired and held closed for 30 seconds. The stapler was then loosened and removed. Suture line was then examined for completeness and for any tear.

\section{Post-operative management}

Patients were managed in the surgery ward. Analgesics were given on demand. Anal canal was examined the next day for any bleeding. If no complications occurred, patients were discharged the following day. All the post-operative complications were noted and the pain was assessed by visual analogue score. At 3 weeks, patients were analyzed for the resolution of symptoms and overall satisfaction. Patients were assessed for recurrence at 1 and 6 months.

\section{Statistical analysis}

Statistical analysis was performed using SPSS 22.0 software (IBM, New York, USA). Results were considered statistically significant if $\mathrm{p} \leq 0.05$. Both the groups were compared by Student's test for parametric measurement and Mann Whitney U test for non-parametric measurements while analysing numerical values. In case of comparison for categorical values, Pearson`s Chi-Square test was used for parmetric measurement and Fisher`s exact correct test for non-parametric measurements. 


\section{Results}

In a study period of two years, total eighty patients of haemorrhoids being equally divided in two groups of 40 each ( Trans anal suture rectopexy - TR and Stappled haemorrhoidopexy - SH ) were enrolled for the present study. After the surgery, all the patients were followed for a minimum period of 6 months.

The mean age of patients was 50.1 years \pm 14.3 ( Range $23-78$ years ) in TR group while it was 45.8 years \pm 14.09 ( Range $21-76$ ) years in SH group with a ' $\mathrm{P}$ ' value of 0.181 . There were 15 females ( $37.5 \%$ ) in TR group while in SH group the count of female was $12(30 \%)$. This difference was statistically insignificant ( $\mathrm{P}=0.637$ ). The mean duration of symptoms was $24.1 \pm 10.8$ and $21.9 \pm 13.1$ months in TR and $\mathrm{SH}$ groups respectively with difference being insignificant $(\mathrm{P}=0.244)$. When the severity of haemorrhoids was considered, there were 23 patients of second degree, 14 patients of third degree and only 3 patients of fourth degree haemorrhoids in TR group. In SH group, this count was 29, 6 and 4 for second, third and fourth degree haemorrhoids respectively. The difference between the two groups was insignificant $(\mathrm{P}=0.111)$.

Table: 1 Demographic and clinical characteristics of both the groups

\begin{tabular}{|l|l|l|l|}
\hline Characteristics & TR Group $(\mathrm{n}=40)$ & SH Group $(\mathrm{n}=40)$ & $p$ value \\
\hline Age in years & $50.1 \pm 14.3$ & $45.8 \pm 14.09$ & 0.181 \\
\hline Females & $15(37.5 \%)$ & $12(30 \%)$ & 0.637 \\
\hline $\begin{array}{l}\text { Mean durations of symptoms in } \\
\text { months }\end{array}$ & $24.1 \pm 10.8$ & $21.9 \pm 13.1$ & 0.244 \\
\hline Grade of the haemorrhoids & $\begin{array}{l}\text { II }-23 \\
\text { III }-14\end{array}$ & $\begin{array}{l}\text { II }-29 \\
\text { III }-6 \\
\text { IV }-4\end{array}$ & 0.111 \\
\hline
\end{tabular}

The mean operative time was $37.0 \pm 6$. Minutes and $35.9 \pm 6.28$ minutes for TR and SH group respectively. The difference was not significant $(\mathrm{P}=0.457)$. The VAS score at post-operative period of 12,24 and 48 hours for the two groups is given in Table 2 . The difference was statistically significant at 12 hours while it was insignificant at 24 and 48 hours of surgery. The mean requirement of doses of analgesic diclofenac sodium was 0.85 and 1.5 for the TR and $\mathrm{SH}$ group respectively. This difference was significant $(\mathrm{P}=0.00)$. Five patients in SH group and one patient in TR group developed post-op urinary retention which was managed by the use of K-90 catheter. This difference was insignificant ( $\mathrm{P}=0.90)$. Post-op bleeding before discharge was present in five patients of SH group and two patients of TR group, which was managed by gauze packing and laxatives. Three patients of SH group and two patients of TR group developed prolapsed before discharge from the hospital only, which was managed by manual reduction and packing. The difference between the two groups was insignificant in terms of both post-operative bleeding and prolapse. The total mean duration of hospitalization was significantly lower in TR group $(\mathrm{P}=.002)$

Per rectal bleeding at one month of follow up was present in four patients of SH group and two patients of TR group with the difference being insignificant ( $\mathrm{P}=0.396$ ). Four patients in $\mathrm{SH}$ group developed prolapse at one month of post-op period, while in TR group this count was zero. The difference was significant $(\mathrm{P}=$ 0.040 ). The patients were managed conservatively by laxatives and sitz bath.At six months of follow up seven patients of SH group had per rectal bleeding while only one patient from TR group has developed bleeding. This difference was significant. ( $\mathrm{P}=0.025)$. Four patients of the SH group had prolapse while no patient of TR group still had developed prolapsed at six month, and this difference too was significant ( $\mathrm{P}=0.40$ ).

At six months, patient significantly rated Transanal suture rectopexy as a better procedure than stappled haemorrhoidopexy.

Table 2: Post-op complications and follow up

\begin{tabular}{|c|c|c|c|}
\hline Features & TR Group $(n=40)$ & SH Group $(n=40)$ & $p$ value \\
\hline Operative time in minutes & $37.0 \pm 6$ & $35.9 \pm 6.28$ & 0.457 \\
\hline VAS score (mean) & $\begin{array}{r}\text { At } 12 \text { hours }-2.10 \\
24 \text { hours }-1.50 \\
48 \text { hours }-1.40 \\
\end{array}$ & $\begin{array}{r}12 \text { hours }-2.50 \\
24 \text { hours }-1.57 \\
48 \text { hours }-1.42 \\
\end{array}$ & $\begin{array}{l}0.041 \\
0.589 \\
0.823\end{array}$ \\
\hline $\begin{array}{l}\begin{array}{l}\text { Dosage of analgesic required } \\
\text { (mean) }\end{array} \\
\end{array}$ & 0.85 & 1.5 & 0.00 \\
\hline Post-op complication & $\begin{array}{l}\text { Urinary retention }-1(2.5 \%) \\
\text { Bleeding }-2(5 \%) \\
\text { Prolapse }-2(5 \%)\end{array}$ & $\begin{array}{l}\text { Urinary retention }-5(12.5 \%) \\
\text { Bleeding }-5(12.5 \%) \\
\text { Prolapse }-3(7.5 \%)\end{array}$ & $\begin{array}{l}0.90 \\
0.432 \\
1.00 \\
\end{array}$ \\
\hline $\begin{array}{l}\text { Duration of hospitalization in } \\
\text { days }\end{array}$ & 1.22 & 1.65 & 0.02 \\
\hline Follow up at 1 month & $\begin{array}{l}\text { Bleeding }-2(5 \%) \\
\text { Prolapse }-0(0 \%)\end{array}$ & $\begin{array}{l}\text { Bleeding }-4(10 \%) \\
\text { Prolapse - } 4(10 \%)\end{array}$ & $\begin{array}{l}0.396 \\
0.40\end{array}$ \\
\hline
\end{tabular}


Comparison Of Transanal Suture Rectopexy With Stapled Haemorrhoidopexy...

\begin{tabular}{|l|l|l|l|}
\hline Follow up at 6 months & Bleeding $-1(2.5 \%)$ & $\begin{array}{l}\text { Bleeding }-7(17.5 \%) \\
\text { Prolapse }-4(10 \%)\end{array}$ & $\begin{array}{l}0.025 \\
0.40\end{array}$ \\
\hline Patient rating & Poor -0 & Poor $-4(10 \%)$ & 0.00 \\
& Fair $-4(10 \%)$ & Fair $-21(52 \%)$ & \\
& Good $-12(30 \%)$ & Good $-7(17.5 \%)$ & \\
& Excellent $-24(60 \%)$ & Excellent $-8(20 \%)$ & \\
\hline
\end{tabular}

\section{Discussion}

The search for a perfect solution to the problem of haemorrhoids is a global effort. Though all the present surgical techniques provide resolution in symptoms to a satisfactory level, post-op complications and recurrence remains a constant problem.

In this randomized control trial of 80 patients, we evaluated the newly introduced technique of transanal suture rectopexy with the stappled haemorrhoidopexy. Both the procedures were comparable with respect to mean operating time, post-op discomfort, urinary retention, post-op bleeding and resolution of symptoms. But the transanal suture rectopexy proved to be significantly better in terms of post-op perianal pain, duration of hospitalization and recurrence of symptoms of haemorrhoids. Our results proved transanal suture rectopexy to be an effective treatment for haemorrhoids and a better alternative to current modalities in terms of post-op pain and recurrence.

The three prominent mucosal folds in anal canal above the dentate line are termed as anal cushions. These are made up of clusters of normally sacculated veins of superior rectal venous plexus and are supplied by arteriovenous anastomses ${ }^{9}$. The important role of anal cushion is in sensing pressure and fullness in anal canal, supports continence and protects anal sphincter from injury ${ }^{10}$. The engorgement and prolapse of these anal cushions due to different reasons leads to symptoms of haemorrhoids.

Most of the earlier treatment modalities of haemorrhoids like Milligan-Morgan or Ferguson technique aimed at cutting the blood supply to the fragile prolapsed part of the pile mass or their removal. Newer techniques like DGHAL and stappled haemorrhoidopexy avoids the removal of these important anatomical structures ${ }^{11}$.

Still, the procedures which involve haemorrhoidectomy have low recurrence but more pain ${ }^{13}$ while the procedures which do not involve haemorrhoidectomy causes less pain but have more recurrence ${ }^{14}$.

Stappled haemorrhoidectomy involves purse string suturing, which is a burdensome task in the settings of prolapsed and swollen haemorrhoids with fragile mucosa. If the suture come too close to dentate line, it may result in severe post-operative pain or if the suture line misses a part of mucosa, it may follow post-operative bleeding. This problem is addressed in this new technique by use of Chivate`s self illuminated slit with sliding valve proctoscope ${ }^{5}$. The illumination with sliding valve mechanism provides a better view, thus avoiding the dentate line and also better suturing. Since there is no resection and auto suturing of mucosa involved, the rate of post-op bleeding is also less when compared to stappled haemorrhoidopexy where incomplete or thin donut may cause post-op bleeding ${ }^{15}$.

The stappled haemorrhoidopexy do has some threat of involvement of rectal wall and posterior vaginal wall, which may result in severe pelvic sepsis ${ }^{16,17}$. There are no chances of such complication in transanal suture rectopexy $y^{5}$ and is a technically safe procedure.

Transanal suture rectopexy demands circumferential double interlocking of the submucosa and mucosa of the anal canal at the level of $2 \mathrm{~cm}$ and $4 \mathrm{~cm}$ above the dentate line. This results in the ligation of haemorrhoidal vessels and fixation of lax mucosa at two places thus preventing the long time recurrences due to collateral formations. This explains the low recurrence rate in our study. While, in the stappled haemorrhoidopexy the chances of recurrence are from 0 to $53.3 \%^{14}$. The incompleteness of the suture line, level of the ring may do affect the long term outcomes. But even when the suture ring is perfect, the formation of collaterals by branches of the superior rectal artery contributes to the high recurrence rates.

\section{Conclusion}

In conclusion, TR and SH both gives satisfactory results in the treatment of haemorrhoids but TR provides less recurrence rates. Use of Chivate`s anoscope makes it an easy procedure with minimal learning curve. The less post-operative pain, less cost makes it an attractive option for both the patients and surgeons. More studies are needed to declare it as a standard procedure for the cure of the disease of haemorrhoids.

\section{References}

[1]. Parks AG. De haemorrhoids: a study in surgical history. Guys Hosp Rep. 1955;104:135-156.

[2]. Loder P. B., Kamm M. A., Nicholls R. J., Phillips R. K. S. Haemorrhoids: pathology, pathophysiology and aetiology. The British Journal of Surgery. 1994;81(7):946-954. doi: 10.1002/bjs.1800810707.

[3]. Longo A (1998) Treatment of hemorrhoids disease by reduction of mucosa and haemorrhoidal prolapse with a circular suturing device: a new procedure; in Proceed. 6th World Congr Endoscop Surg, Rome, June 3-6 
[4]. Morinaga K, Hasuda K, Ikeda Y. A noveI therapy for internal haemorrhoids: ligation of the haemorrhoidal artery with a newly devised instrument (Moricorn) in conjunction with a Doppler flowmeter. Am J Gastroenterol. 1995;90:610-613.

[5]. Shantikumar D. Chivate et al, Transanal Suture Rectopexy for Haemorrhoids: Chivate's Painless Cure for Piles, Indian J Surg. 2012 Oct; 74(5): 412-417

[6]. Kaidar-Person O, Person B, Wexner SD. Hemorrhoidal disease: A comprehensive review. J Am Coll Surg. $2007 ; 204: 102-117$.

[7]. Varut Lohsiriwat, Hemorrhoids: from basic pathology to clinical management, World J Gastroenterol. 2012 May 7; 18(17): 20092017.

[8]. Goligher J. C. Surgery of the Anus, Rectum and Colon. 4th. London, UK (Baillere Tindall; 1980. Haemorrhoids or piles; pp. 93135.)

[9]. Gibbons CP, Trowbridge EA, Bannister JJ, Read NW. Role of anal cushions in continence. Lancet.1986;1:886-888. doi: 10.1016/S0140-6736(86)90990-6.

[10]. Schubert M. C., Sridhar S., Schade R. R., Wexner S. D. What every gastroenterologist needs to know about common anorectal disorders. World Journal of Gastroenterology. 2009;15(26):3201-3209. doi: 10.3748/wjg.15.3201

[11]. Haemorrhoids: modern diagnosis and treatment. Hollingshead JR, Phillips RK, Postgrad Med J. 2016 Jan; $92(1083)$ :4-8

[12]. Pain after Haemorrhoidectomy Br Med J. 1965 Sep 18; 2(5463): 659-660.

[13]. American Gastroenterological Association medical position statement: diagnosis and treatment of hemorrhoids. Gastroenterology. 2004;126(5):1461-1462. doi: 10.1053/j.gastro.2004.03.001.

[14]. Long-term Outcomes of Stapled Hemorrhoidopexy vs Conventional HemorrhoidectomyA Meta-analysis of Randomized Controlled Trials, Pasquale Giordano, MD, FRCSEd, FRCS; Gianpiero Gravante, MD; Roberto Sorge, PhD; Lauren Ovens, MBChB, MRCS; Piero Nastro, MD, MRCS, Arch Surg. 2009;144(3):266-272. doi:10.1001/archsurg.2008.591.

[15]. Halberg M, Raahave D, Rosens Kvarter 3, DK-2990 Niva. Perirectal, retroperitineal, intraperitoneal and mediastinal gas after stapled haemorrhoidapexy. Halberg@ helleberg.Dk

[16]. Life threatening pelvic sepsis after stapled haemorrhoidectomy. Molloy RG, Kingsmore D, Lancet. 2000 Mar 4; 355(9206):810.

[17]. Reinterventions after complicated or failed stapled hemorrhoidopexy. Brusciano L, Ayabaca SM, Pescatori M, Accarpio GM, Dodi G, Cavallari F, Ravo B, Annibali R, Dis Colon Rectum. 2004 Nov; 47(11):1846-51. 